Biannual Research Journal Grassroots

Vol.55, No.II, 2021: 255-276

Grassroots

ASSESSING RELATIONSHIP BETWEEN EXCHANGE RATE AND STOCK RETURNS: A CASE OF PSX

\author{
Rabia Sabri \\ Senior Lecturer, Department of Professional \& Commercial Studies, \\ Institute of Business Management (IoBM), Karachi-Pakistan \\ Email: rabia.sabri@iobm.edu.pk \\ Masood Hassan \\ PhD Scholar, College of Business Management (CBM), \\ Institute of Business Management, Karachi-Pakistan \\ Email: masoodhassan1@hotmail.com, std 21855@iobm.edu.pk \\ M. Asad Ullah \\ Lecturer, Department of Professional \& Commercial Studies, \\ Institute of Business Management (IoBM), Karachi-Pakistan \\ Email: $\underline{\text { m.asadullah@iobm.edu.pk }}$
}

\begin{abstract}
The aim of the research was to analyse the relationship between stock returns (KSE-100 index) and USDPKR exchange rate. Additionally, the analysis was conducted separately for Khan's and Sharif's era. In order to attain this aim, VAR and SVAR models were used. The sample was considered from June 2010 to June 2019 of monthly frequency related to stock returns and exchange rates. The results inferred that there was no relationship found between $F X$ returns and stock returns in the case of Pakistan. However, a minor unidirectional relationship was found which implied that the stock returns were Granger-caused by exchange rate returns at 10\% significance level. Besides, analysing Khan's and Sharif's regime separately, no significant association was found between exchange rate returns and stock returns. This research is the first one where Khan and Sharif's have been analysed separately in the context of FX returns and stock returns. The results implied that the theories related to no relationship between exchange rates and stock returns are sustained but a minor association was found. The underlying reason for such behaviour can be regarded as a result of psychological influence on the investors of the deteriorating value of PKR affecting their investments in the stock market.
\end{abstract}

Keywords: Stock returns, exchange rate, PSX, KSE-100 index, USDPKR, Khan, Sharif, VAR, SVAR

\title{
INTRODUCTION
}

In the economic progress of a country, the contribution of the stock market and foreign exchange market is significant. Therefore, this grabbed the attention of various researchers and they analysed whether exchange rates 
and stock returns of a country are associated or not. According to the study conducted by Khatri, Kashif and Shaikh (2017) on Asian economies, it was empirically tested which revealed that exchange rate cannot predict stock returns, however, a short-run and negative association was found between exchange rate and stock returns in case of Bangladesh and Sri Lanka. There are other researches as well that negate the relationship between the two main variables of this study: exchange rate and stock returns. The research of Suriani, Kumar, Jamil and Muneer (2015) conducted on Pakistan also stated that there exists no association between the stock returns of the undertaken country and its exchange rates. The most significant currency pair from the perspective of Pakistan is USD PKR and following the general elections 2018, the exchange rate was soaring high and has hit its highest during the span in the interbank market (Zubairi, 2019). It implies a strong demand of dollar and declining demand for PKR which can further affect the investments in Pakistan Stock Exchange (PSX). In this concern, Zaidi (2019) stated that dollar is soaring high against PKR and consequently stock market is apparently submerged in the red zone. The underlying reason of market plunges can be associated with the psychological influence on the investors as stated by Asad, Khan and Faiz (2018). Pertaining to the mentioned aspects, the following research has aimed to analyse the relationship between stock returns and exchange rate where the case of USD PKR has been specifically considered.

Moreover, another objective of the study is to examine the eras of Imran Khan and Nawaz Sharif separately. The underlying reason for conducting this research is the limited studies that have been conducted following the regime of Imran Khan in Pakistan. The research carried out by Clerc, Drumetz and Haas (2002) opined that new government influences the market dynamics and its related functioning. Therefore, the reign of Khan has also brought certain changes in the structure and functioning of the equity market in Pakistan along with fluctuation in the exchange rates to the core. The research of Gay (2016) asserted that the government's policy intervenes the financial market dynamics therefore, both the stock market and foreign exchange market (FX) comes under it. Hence, it would be beneficial to analyse whether there is an association between FX returns and stocks returns in any of the undertaken eras.

However, concerning the core of the research which is the relationship between stock returns and FX returns, the research of Suriani et.al., (2015) can be regarded as one of the significant studies. Therefore, to provide latest evidence, this research is highly significant which can help the policy-makers of the country to devise policies in favour of the country considering the findings of the study whilst it is also significant for the potential investors interested to inject in PSX and are concerned for FX fluctuations. 
Concerning the identified gap and aim mentioned, the following objectives have been designed to be studied and tested in this study:

- To determine the association between stock returns and exchange rate fluctuations in the case of PSX and USDPKR.

- To analyse whether there is an association between stock returns and FX returns or not in Sharif's term and Khan's term separately.

The research can be deemed as highly significant for the precise comprehension of the PSX and FX dynamism. Moreover, the following research will also contribute significantly to the academic literature specific to Pakistan and can guide the future researchers of the similar domain to conduct testing on other governmental changes on the undertaken markets (PSX and FX). In this concern, the main research question which has been answered is as follows: "Is there any significant association between stocks returns of the companies listed in PSX and exchange rate of USD/ PKR?"

\section{Designing Hypotheses}

Pertaining to the research objectives, aim and question demarcated in the previous section, the following hypotheses have been constructed that are tested in the next sections of the article:

$\mathrm{H}_{1}$ : The association of stock returns of the companies listed in PSX with the exchange rate fluctuations (USD PKR) is statistically significant

$\mathrm{H}_{2}$ : There is a significant relationship between FX returns and stock returns in Khan and Sharif's era

The aforementioned hypotheses have been tested at $5 \%(.05)$ significance level which can also be regarded as the cut-off point of the following study.

\section{LITERATURE REVIEW}

The studies conducted on the assessment of the association of exchange rates with the stock returns and vice versa are in abundance. These researches have been conducted in different countries that exhibited variable characteristics and produced diverse results. The relationships evaluated by authors are both in long-term and short-term using various techniques. Pertaining to the objective of the following study based on PKR USD and stock returns, similar research was carried out by Suriani et.al., (2015) on KSE-100 index. The study asserted both the stock market and exchange rate market as significant representatives of financial markets globally. The undertaken currency pair was USD/PKR whilst the data was of monthly frequency and considered period was ranging from 2004 to 2009 which can be deemed as a time period of the reign of Pakistan Muslim League (Q) and Pakistan People's Party Parliamentarians (PPPP). Under the mentioned 
reigns, the relationship was found to be insignificant therefore, both were declared to be independent of each other.

The fluctuation in the exchange rates of a country is dependent upon the demand and the supply which is a similar phenomenon like a commodity (Evans, 2014). In this essence, the research of Chatterjee and Mursagulov (2016) professed the contribution of fiscal policies devised and implemented by the government. Concerning the phenomenon of government's intervention, the dynamics of both the stock market and exchange rate alters and the research of Caporale, Hunter and Menla (2013) explained these alterations in the context of structural breaks. Besides, the research conducted on China explained the effect of structural changes pertaining to the government's bail-out policies on the stock returns which were found to be significant (Wang et.al., 2017). Moreover, the study of Abbas (2010) asserted that relative Purchasing Power Parity (PPP) entails that the changes in the exchange rate pair proportionate to changes in the domestic price levels altering the inflation levels and various authors have studied dynamics of stock market in the context of inflation, for instance; the study of Tripathi and Kumar (2014). The aforementioned aspects indicate the indirect association of exchange rates with the stock price dynamics.

On the other hand, Hussain and Khan (2014) conducted research of Pakistan's pharmaceutical industry in similar where the relationship of the exchange rate was tested with the stock returns. The mentioned study surmised that there is a negative but significant association of PKR USD currency pair with the stock returns specifically in the short-run. The research further stated that in the case of floating exchange rates, the international companies start losing their edge in the competition. However, the research of Huang (2017) stated that when the local currency depreciates then the multinational corporations operating domestically gains over the local rivals. Besides, another research stated that alterations in the exchange rate specifically when it appreciates, the exports of the country are affected along with the input costs which results in a significant influence on the local stock market (Sichoongwe, 2016).

In addition, another research on the developing nation- India as conducted by Sharma (2016) inferred the co-integrating relationship between stock market returns and exchange rate whilst the correlation was computed to be negative and causal relationship was also found using Grangercausality testing which was bidirectional. However, the aforesaid research was conducted on different sector therefore, the causal relationship in the case of media and the pharmaceutical sector was computed to be unidirectional.

Proceeding further on the studies on developing countries, the research of Zhao (2010) conducted a study on China using monthly data ranging from 
1991 to 2009 in the similar scenario where the influence of exchange rate dynamics on the stock returns. The results inferred that the effect in the longrun was null of the exchange rate on the stock returns using GARCH and VAR statistical techniques. Besides, the mentioned research also tested to analyse cross-volatilities and following the analysis, it was revealed that the spill-over effect pertaining to volatility was found as bidirectional.

On the other hand, the research carried out by Diamandis and Drakos (2011) examined the long-term association in the case of Mexico, Chile, Brazil and Argentina whilst short-term dynamics were also studied using cointegration analysis along with Granger-causality. The aforementioned research could not find any significant association yet the inclusion of USA's stock market exhibited positive association. Although the interaction does not rely on the choice of the sample (Davidson et.al., 2013), however, the study of Haughton and Iglesias (2017) found that few co-integrating coefficients were stable in the context of instability tests over a particular span.

In addition to discussed studies, another research pertaining to the problem of relationship assessment between stock returns and different currency pairs in the context of six South Asian nations was carried out by Tsai (2012). The undertaken countries incorporated Malaysia, Thailand, Singapore, Taiwan, South Korea and the Philippines. In this context, the countries are evidently a mixture of developing and developed nations. The specific methodology of the aforesaid research was quintile regression and the association of the said variables was negative and was backed by the portfolio-balancing effect which states that increment in returns affects the index positively resulting in the decrement of the exchange rate (Camanho et.al., 2018). Given this, the research found a heterogeneous effect across the undertaken countries yet the effect of returns on the exchange rate was significant. However, this research examined an effect which is converse of the subject of the following study. On the contrary, the research of Ali and Haider (2005) found contrary findings conducted on four Asian countries from the period of 1994 to 2000 . The research inferred on the basis of cointegration testing along with Granger-causality that both the variables were independent of each other. The aforesaid study also undertook Pakistan in the short-term case yet the findings were consistently independent of each other. Nevertheless, the study took both nominal and real exchange rates which were strongly correlated with prices but the relationship was insignificant. The findings in the mentioned context were found to be supported by other studies for instance; the study conducted in India (Bhattacharya \& Mukherjee, 2003). Nonetheless, the literature review revealed variability in the findings of different researches conducted on different countries empirically. 


\section{RESEARCH METHODOLOGY}

In order to attain the aim and research objectives, the following research follows a quantitative research design as the association of stock returns has been tested with the exchange rate. The research conducted by Creswell and Creswell (2017) stated that using a quantitative design substantiates the analysis and research findings in an empirical manner. Concerning this aspect, the approach towards the following research is deductive. Glaser (2014) explained the deductive approach by stating that it tests the pre-existing theories while another approach is inductive where theory is devised subsequently to a thorough and meticulous analysis and observation. Since the relationship is already tested by various authors and researcher in different contexts, therefore, pertaining to the development in the state politics of Pakistan and regime of Khan, this research has tested the case of PSX in a structural context which justifies the deductive research approach.

On the other hand, the method undertaken towards data collection is secondary which is sufficiently appropriate with respect to the nature of the study. The data has been obtained from sources like Yahoo Finance and Investing.com that are open sources, easily accessible and accounts no cost yet are authentic. The undertaken time ranges from July 2010 to July 2019 which forms 9 years. In addition, the frequency of the data undertake in the research is monthly while the variables considered are monthly stock prices based on KSE-10 index and USD/PKR exchange rate. Firstly, the returns have been computed using the following formula:

Returns $=\operatorname{Ln}\left(\frac{P_{t}}{P_{t-1}}\right)$

The log returns have been computed where Pt is representing the price at the current time period whilst $\mathrm{P}(\mathrm{t}-1)$ is representing the price at the previous time period. Since the data was time-series therefore, stationarity has been tested on priority using unit root testing on E-Views with the help of Augmented Dickey-Fuller (ADF) test. After the confirmation of the stationarity of the data, the researcher utilised Vector Auto-Regression (VAR) model. Moreover, it is also supported by graphical analysis of the variables along with descriptive statistics. The underlying reason for using VAR is better explained by Kilian and Lütkepohl (2017) that in the case of stationary data which is time-series, the interdependencies of two or more time-series variables in a linear manner can be tested. Therefore, it fulfils the purpose and objective of this study seemingly where the relationship between the exchange rate and the stock returns. Given this, another cause of choosing such a technique is associated with different studies using this approach as discussed in the empirical literature review. The study of Zhao (2010) implemented the same technique to devise whether there is a 
relationship between the two or not. In addition, structural restrictions have been further tested on the data using SVAR while to test second hypotheses of the study, the researcher has conducted separate analysis on both regimes. The inference has been made on the analysis and specifically on the basis of impulse responses generated.

\section{EMPIRICAL ANALYSIS}

The methodology of the research has been finically outlined and elaborated in the previous section which has been implemented in this section to devise and interpret the given results. Firstly, the unit root testing has been done for both variables: exchange rate and stock returns following the computation of their returns with the help of given formula in the methodology. Subsequently, ADF test has been applied which inferred that both series are statistically stationary because the p-values of both series were below 0.05 ( $5 \%$ significance level). Thus, the null hypothesis of the given variables was rejected which was pertaining to the presence of unit root. This step validated the use of VAR, however, firstly descriptive statistics have been computed to analyse the central tendency measures of the data, its dispersion behaviour and data's skewness. The results of descriptive statistics can be viewed as follows:

\begin{tabular}{|c|c|c|c|}
\hline & Stock Returns & USDPKR & FX Returns \\
\hline Mean & $1.16 \%$ & 103.91 & $0.60 \%$ \\
\hline Median & $1.93 \%$ & 103.44 & $0.12 \%$ \\
\hline Maximum & $13.95 \%$ & 163.13 & $10.44 \%$ \\
\hline Minimum & $-11.03 \%$ & 84.73 & $-6.50 \%$ \\
\hline Standard Deviation & $5.03 \%$ & 14.80 & $1.81 \%$ \\
\hline Skewness & -0.25 & 1.50 & 1.96 \\
\hline Kurtosis & 2.85 & 5.77 & 14.12 \\
\hline
\end{tabular}

In accordance with the table of descriptive statistics, the mean stock return over the span of 9 years is computed to be $1.16 \%$ with a median $\left(50^{\text {th }}\right.$ percentile) is computed to be $1.93 \%$ which is slightly higher. Given this, the maximum returns generated on a monthly basis can be seen as $13.95 \%$ whilst the minimum returns are computed to be $-11.03 \%$. This implies an extensive range exhibiting characteristics of high dispersion of data over the time period. In the same concern, the standard deviation can be seen as avidly higher than the mean itself which is representing high variance in the KSE100 index returns. In addition, the data stream of stock returns can be seen having negative skewness with a thick tail as the kurtosis value is positive. 
On the other hand, one USD is traded for PKR 103.91 on an average as per mean value while the median value is also closer which can be seen as 103.44 over the span of 9 years. The depreciation of PKR in 9 years reach to the point where 1 USD has been traded on PKR 163.13 which happened in the regime of Khan. While the minimum trading value is quite lower as 1 USD was traded for PKR 84.73 in Sharif's regime. This further asserts high range but the deviation is moderate. Also, the increase is not as sharp as the data is thick-tailed pertaining to the exchange rate.

Besides, another key variable of the study is FX returns obtained from USDPKR exchange rate. The mean return is obtained to be $0.60 \%$ with a median value of $0.12 \%$. In addition, the maximum yield pertaining to the currency pair is of $10.44 \%$ whereas, the minimum yield is computed to be $6.50 \%$. The data has a high deviation in comparison with mean value, however, it is relatively lower than the deviation in stock returns. Given this, the data is positively skewed with a thick tail. Moreover, to analyse the trend or seasonality in the data, the graphical diagnosis has been conducted as follows.

KSE-100 index

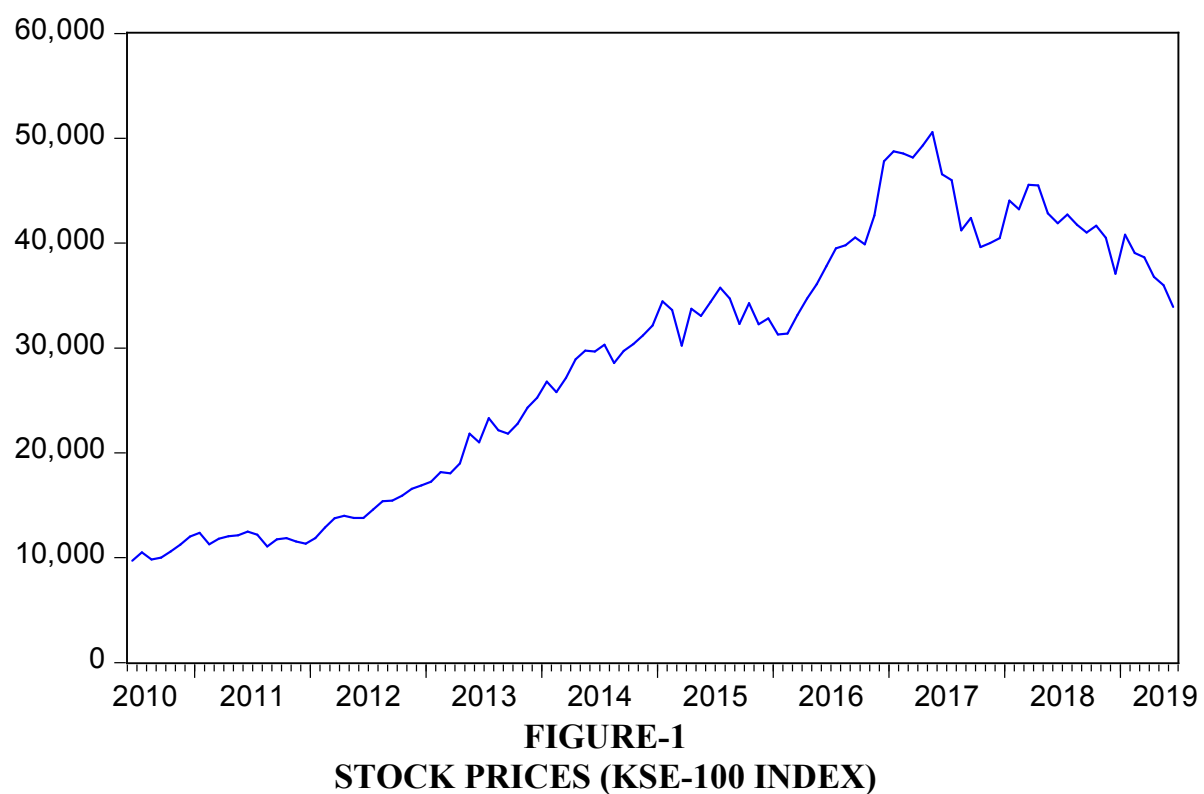

With respect to the graph presented above, it is quite avid that the stock returns are following a linear incremental trend, however, it is limited to the mid of 2016. Following the mentioned time period, the prices have seen a drop. 
Biannual Research Journal Grassroots Vol.55, No.II: 255-276

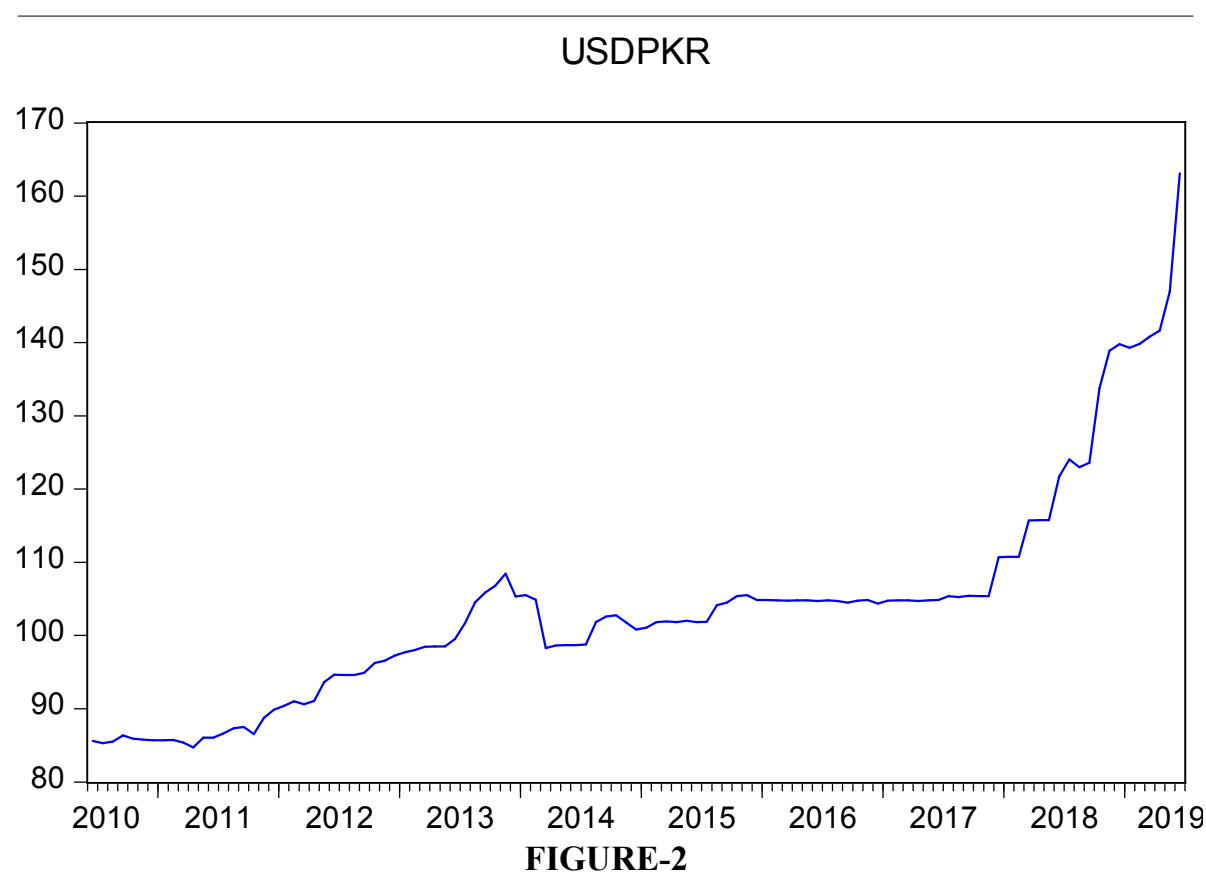

GRAPHICAL REPRESENTATION OF EXCHANGE RATE

The exchange rate is following a linear increasing trend till 2015, however, from 2015 to 2017 , it is visibly constant to a greater extent. Subsequent to this, an exponential surge can be seen and it is the same time period when Khan took the charge of the office. Precisely, it can be inferred that within the span of 9 years, the value of PKR against USD is depreciated to a greater extent. 
Biannual Research Journal Grassroots Vol.55, No.II: 255-276

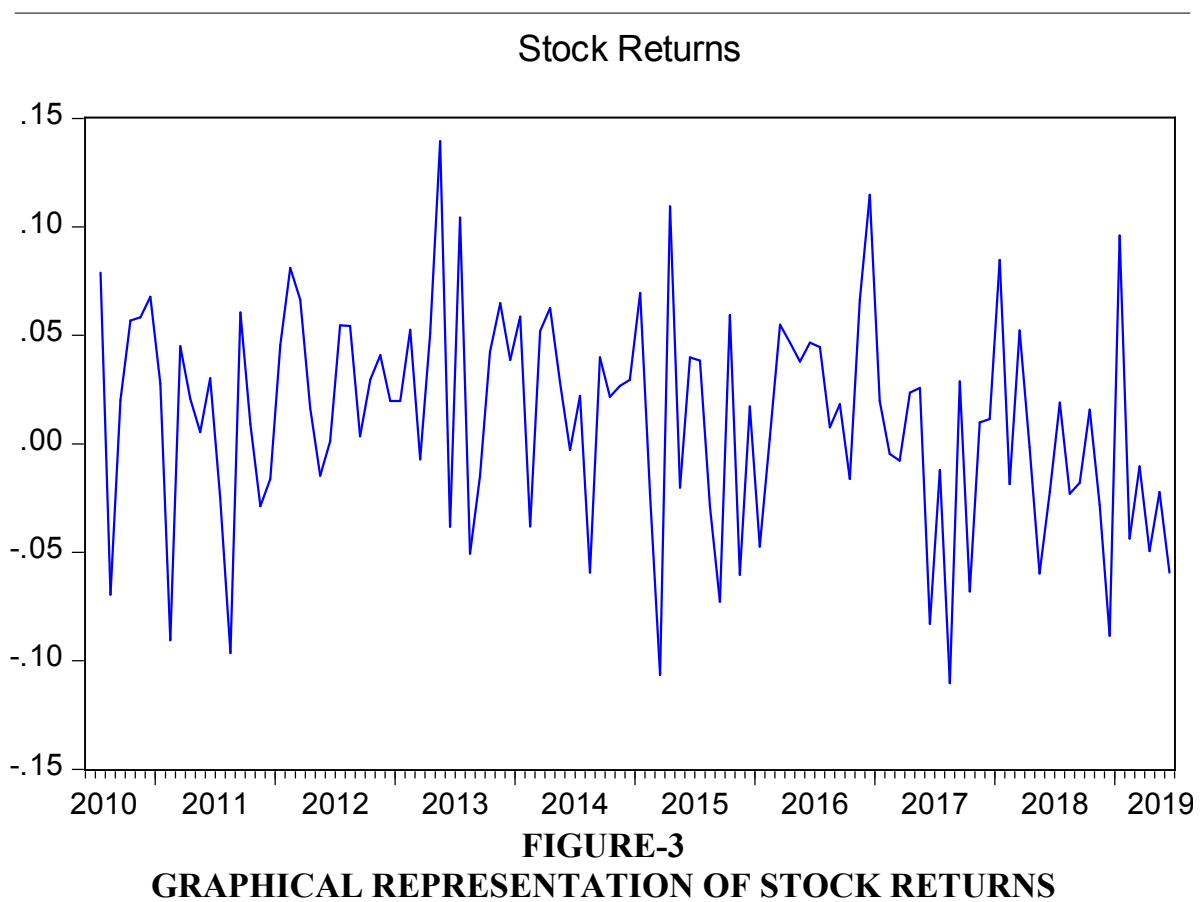

From the figure resented above, it can be inferred that stock returns are highly volatile in nature where it has experienced extreme highs and lows. Moreover, the graphical representation of the exchange rate (USDPKR) returns can be seen as follows: 
Exchange Rate

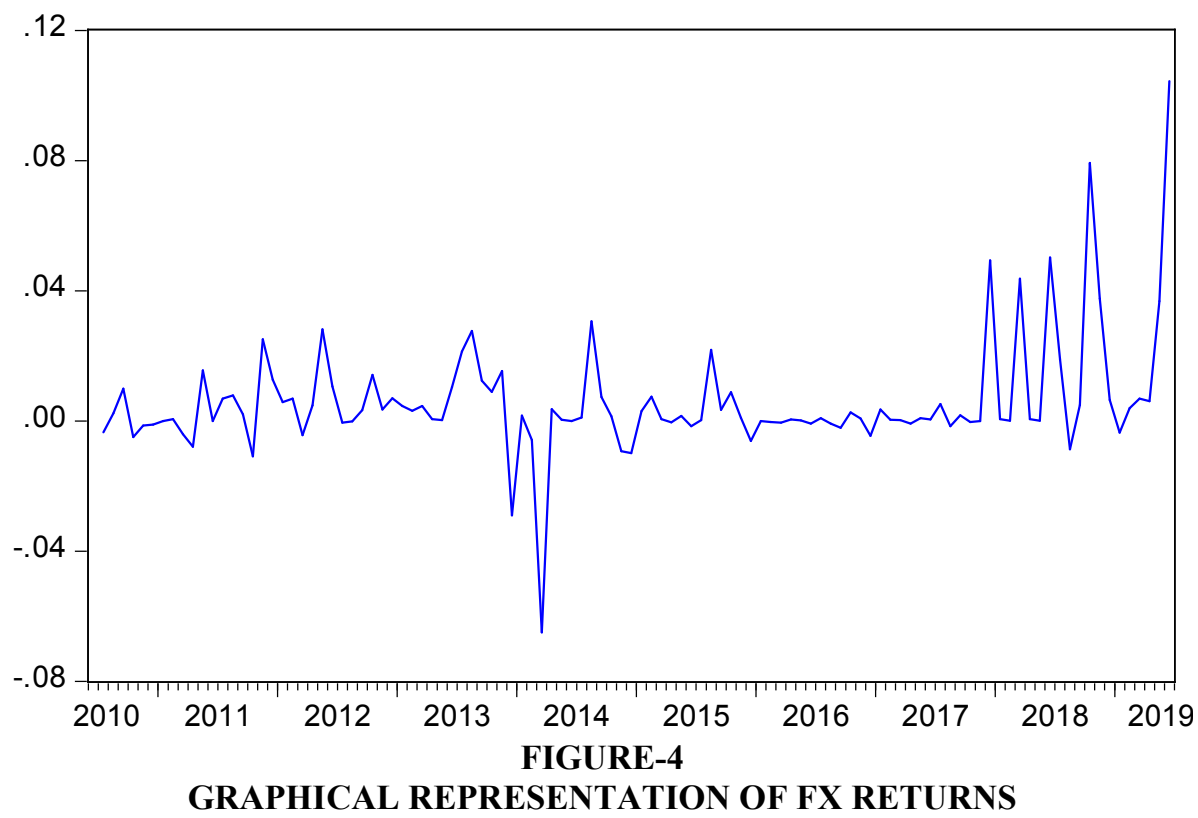

The figure implies that the fluctuations till 2017 are moderate where certain points of arbitrage opportunities came. However, extreme oscillations are visible following 2017 and specifically in the mid and this was the time when Sharif's government in Pakistan left the charge and Khan came into office. Cumulatively, the response of stock prices, exchange rate, and FX returns is avid to the structural change in Pakistan's government. Nonetheless, in the case of stock returns, it is seemingly ambiguous to infer any response.

The graphical analysis and descriptive statistics are followed by a comprehensive VAR analysis of the main variables that are stock returns and FX returns. Firstly, the first hypothesis has been tested therefore, all data comprising of 109 observations has been examined. The lag length criterion has been assessed and found to have one significant lag as per AIC and FPE criterions, however, SIC and log-likelihood ratio (LR) opined no-lag. This entails that it is highly improbable to infer that either of the two variables depends on their lags. The results of the unrestricted VAR can be viewed as follows whilst the lag length is chosen to be one on the basis of the aforementioned reason. 


\begin{tabular}{lll}
\hline \multicolumn{3}{c}{ TABLE-2 } \\
\hline & Exchange Rate & Stock Returns \\
\hline Exchange Rate (-1) & $\mathbf{0 . 2 7 1 5 7 6}$ & $\mathbf{- 0 . 5 3 2 5 9 5}$ \\
& -0.1128 & -0.31645 \\
& {$[2.40763]$} & {$[-1.68301]$} \\
Stock Returns (-1) & -0.031046 & -0.103442 \\
& -0.03489 & -0.09788 \\
& {$[-0.88983]$} & {$[-1.05679]$} \\
& & \\
C & 0.005067 & 0.014892 \\
& -0.00188 & -0.00527 \\
& {$[2.69611]$} & {$[2.82434]$} \\
\hline R-squared & $6.72 \%$ & $3.22 \%$ \\
Adjusted R-squared & $4.93 \%$ & $1.36 \%$ \\
F-statistic & 3.746 & 1.730 \\
Log-likelihood & 281.023 & 170.644 \\
Akaike AIC & -5.197 & -3.134 \\
Schwarz SC & -5.122 & -3.059 \\
\hline Log-likelihood & & 453.58 \\
Akaike information criterion & -8.37 \\
Schwarz criterion & & -8.22 \\
\hline
\end{tabular}

It is visible from the table presented above that FX returns are significantly dependent on its lag value because the critical value at $5 \%$ of $t$ distribution is 1.65 (Berg \& Latin, 2008) whereas the value, in this case, is computed to be 2.40 which is above the critical value. Therefore, it is found to be dependent on its lag. Moreover, another evidence is found where the stock returns are found to be dependent linearly on the first lag of FX returns (t-statistics is $-1.68<-1.65$ ) but, the significance is not strong. Hence, statistical evidence is found where stock returns are negatively but significantly affected by the previous value of exchange rate, however, the converse is found to be untrue. It implies that it is a unidirectional relationship where stock returns are affected by the exchange rate but the exchange is found to be unchanged pertaining to stock returns. In addition, the first model on the basis of R-squared is $6.72 \%$ explaining the variance whereas, the second model is explaining only $3.22 \%$ and adjusted R-squared 
is even lower. Given this, the first model is more significant than the second one on the basis of f-statistics, AIC (lower is preferred), SIC (lower is preferred) and log-likelihood. The preferences are explained and justified by the study of Montgomery et al. (2015) on time-series modelling. Consequently, to test the unidirectional nature, Granger-causality has been further employed in producing the following results:

TABLE-3

GRANGER-CAUSALITY TEST

\begin{tabular}{llll}
\hline Dependent variable: Exchange Rate & Chi-sq & df & Prob. \\
\hline Stock Returns & 0.792 & 1 & 0.37 \\
All & 0.792 & 1 & 0.37 \\
\hline & & & \\
\hline Dependent variable: Stock Returns & Chi-sq & df & Prob. \\
\hline Exchange Rate & 2.833 & 1 & 0.09 \\
All & 2.833 & 1 & 0.09 \\
\hline
\end{tabular}

In light of the results obtained of Granger-causality, the results are supported sufficiently. On the basis of 5\% significance level, both explain and Granger-cause each other insignificantly, however, if the significance level is made flexible to $10 \%$ then, stock returns are explained and GrangerCaused by FX returns significantly. For a more comprehensive elaboration, impulse response has been presented as follows: 
Biannual Research Journal Grassroots Vol.55, No.II: 255-276

Response to Cholesky One S.D. Innovations \pm 2 S.E.

Response of EXCHANGE_RATE to EXCHANGE_RATE

Response of EXCHANGE_RATE to STOCK_RETURNS
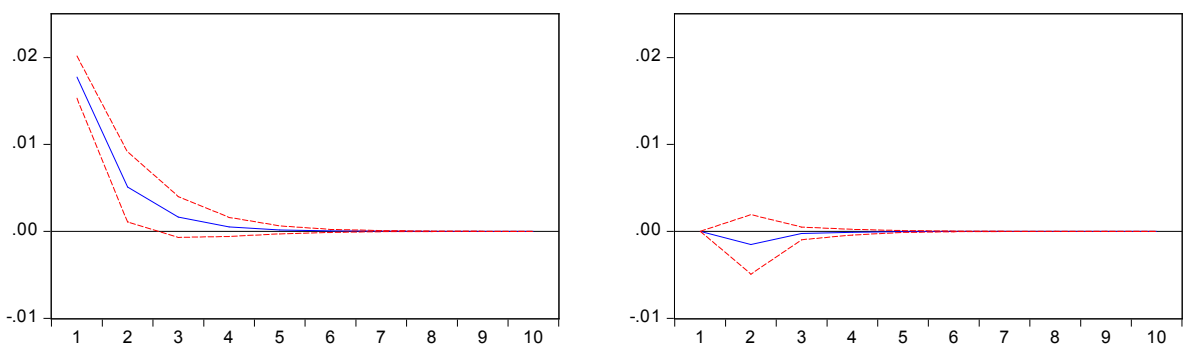

Response of STOCK_RETURNS to EXCHANGE_RATE

Response of STOCK_RETURNS to STOCK_RETURNS
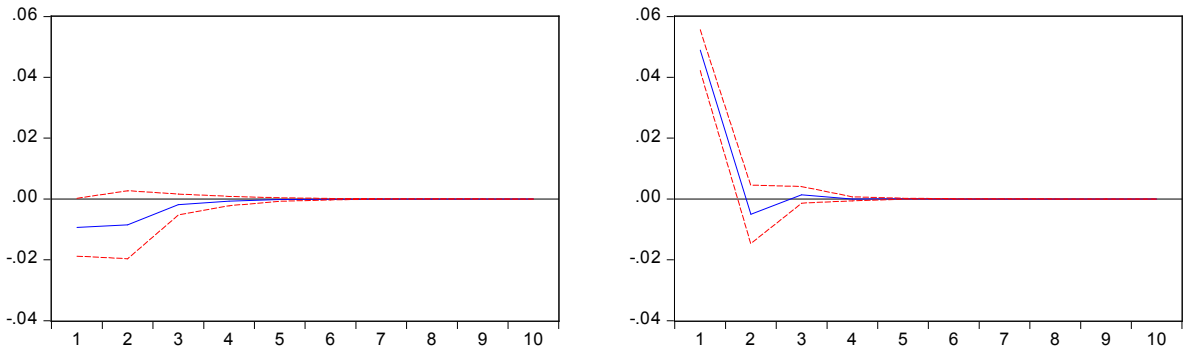

FIGURE-5

IMPULSE RESPONSE BASED ON VAR

In accordance with impulse responses, the response of FX returns to FX returns is significant for the first period only and similar is the case with stock returns' response to stock returns which can be viewed in the last subpicture on left-hand. Given this, all other responses are statistically insignificant. However, the researcher further applied structural restriction both in the long-run and short-run and thus, produced following impulse responses based on economic theories pertaining to exogenous variables: 
Biannual Research Journal Grassroots Vol.55, No.II: 255-276

Response to Structural One S.D. Innovations \pm 2 S.E.

Response of EXCHANGE_RATE to Shock1

Response of EXCHANGE_RATE to Shock2
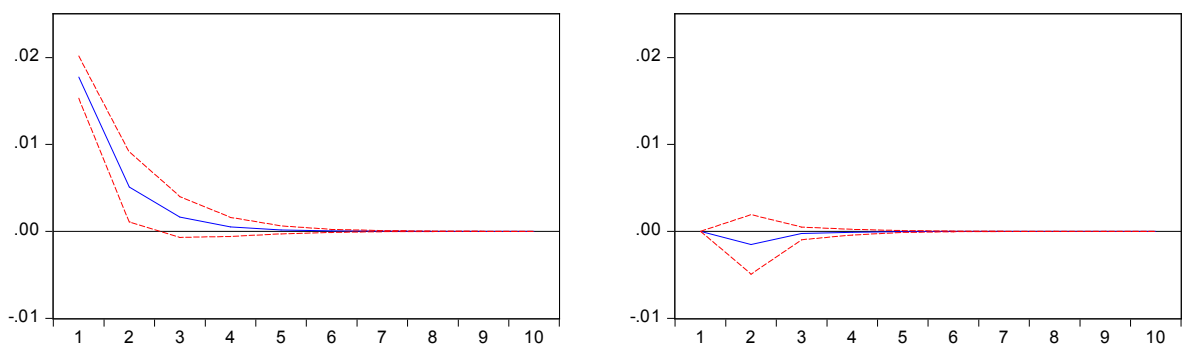

Response of STOCK_RETURNS to Shock1

Response of STOCK_RETURNS to Shock2
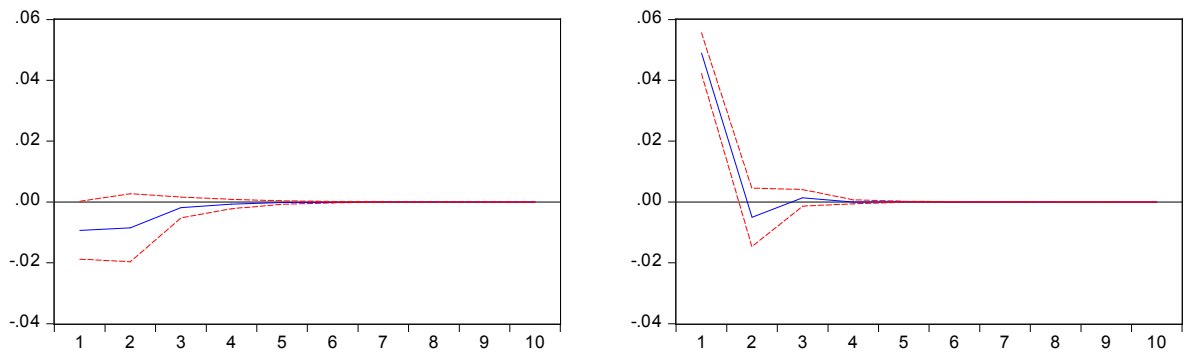

FIGURE-6

IMPULSE RESPONSE BASED ON SVAR (SHORT-RUN)

Even after applying structural restrictions (SVAR), the response is similar to the unrestricted VAR as discussed above specifically in the short run. The long-run impulse response can be viewed below: 
Biannual Research Journal Grassroots Vol.55, No.II: 255-276

Response to Structural One S.D. Innovations

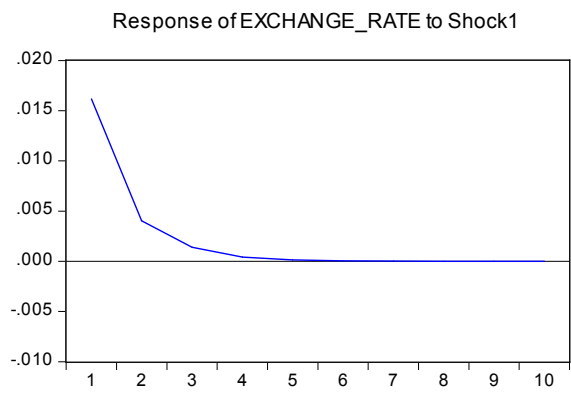

Response of EXCHANGE_RATE to Shock2

Response of STOCK_RETURNS to Shock1
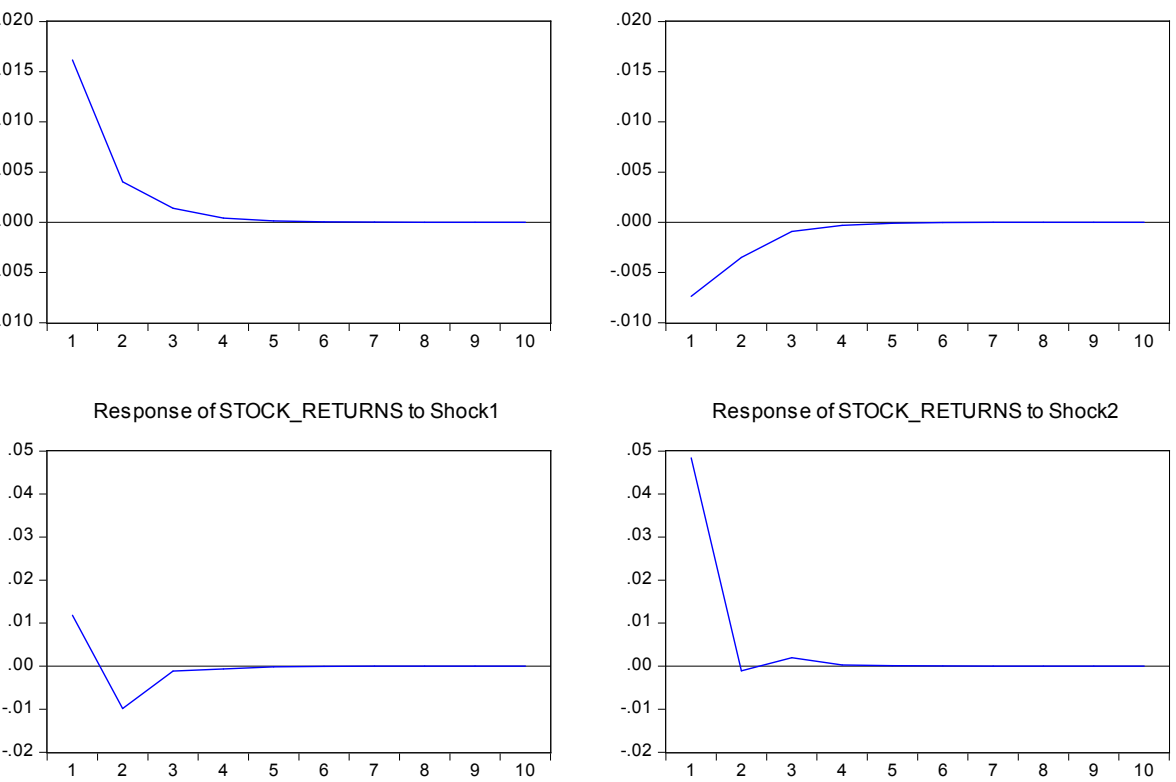

Response of STOCK_RETURNS to Shock2

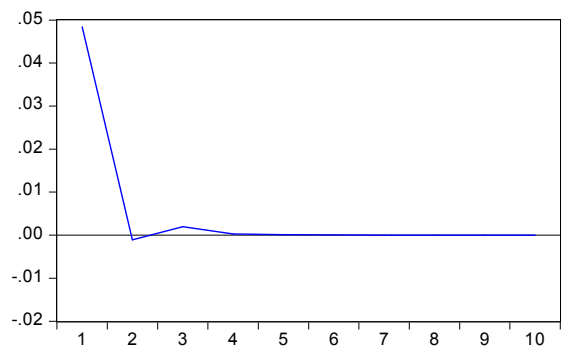

FIGURE-7

IMPULSE RESPONSE BASED ON SVAR (LONG-RUN)

The long-run behaviour is somewhat similar to the short-run but is more avid. However, if stock returns' response to shock 1 is studied then in long-run it firstly declined and then increased whereas, the case with shortrun is different as it did not experience a decline. Moreover, the results pertaining to both regimes in the case of the VAR model have been further computed separately which can be seen as follows:

TABLE-4

ANALYSIS OF SHARIF'S AND KHAN'S REGIME

\begin{tabular}{|c|c|c|c|c|}
\hline & \multicolumn{2}{|c|}{ Sharif's Regime } & \multicolumn{2}{|c|}{ Khan's Regime } \\
\hline & Exchange & Stock & Exchange & Stock \\
\hline \multirow{4}{*}{$\begin{array}{l}\text { Exchange Rate } \\
(-1)\end{array}$} & & & & \\
\hline & 0.116833 & -0.36307 & 0.448576 & -0.50571 \\
\hline & -0.12232 & $\begin{array}{l}-0.42452 \\
{[-}\end{array}$ & -0.48508 & -0.55423 \\
\hline & [ 0.95516$]$ & $0.85525]$ & [ 0.92475$]$ & [-0.91244] \\
\hline
\end{tabular}

Exchange Rate

$\begin{array}{lll}(-2) & -0.053127 & -0.08378\end{array}$ 
Biannual Research Journal Grassroots Vol.55, No.II: 255-276

\begin{tabular}{ll}
\hline-0.13323 & -0.4624 \\
& {$[-$} \\
{$[-0.39875]$} & $0.18119]$
\end{tabular}

Exchange Rate $(-3)$

$\begin{array}{ll}\mathbf{0 . 4 6 2 5} & 0.164996 \\ -0.13306 & -0.46179 \\ & {[} \\ {[3.47590]} & 0.35730]\end{array}$

Stock Returns (1)

$\begin{array}{llll}-0.015239 & -0.13863 & -0.07935 & -0.46345 \\ -0.03692 & -0.12815 & -0.26151 & -0.29879 \\ & {[-} & & \\ {[-0.41272]} & 1.08177] & {[-0.30344]} & {[-1.55107]}\end{array}$

Stock Returns (2)

$\begin{array}{ll}-0.016101 & 0.13904 \\ -0.03684 & -0.12787 \\ & {[} \\ {[-0.43700]} & 1.08737]\end{array}$

Stock Returns (-

\begin{tabular}{lllll} 
3) & 0.049581 & -0.01384 & & \\
& -0.0375 & $\begin{array}{l}-0.13014 \\
{[-}\end{array}$ & & \\
& & & & \\
& {$[1.32220]$} & $0.10636]$ & & \\
& & & & \\
C & 0.0019 & 0.011883 & 0.016107 & -0.01878 \\
& -0.00224 & -0.00777 & -0.01496 & -0.01709 \\
& & {[} & & \\
& {$[0.84856]$} & $1.52895]$ & {$[1.07674]$} & {$[-1.09888]$} \\
\hline R-squared & $21.18 \%$ & $5.98 \%$ & $10.18 \%$ & $30.45 \%$ \\
Adj. R-squared & $12.58 \%$ & $-4.28 \%$ & $-12.28 \%$ & $13.06 \%$ \\
F-statistic & 2.46 & 0.58 & 0.45 & 1.75 \\
Log likelihood & 177.12 & 99.97 & 21.90 & 20.43 \\
Akaike AIC & -5.49 & -3.00 & -3.44 & -3.17 \\
Schwarz SC & -5.25 & -2.76 & -3.33 & -3.06 \\
\cline { 2 - 5 } & & & &
\end{tabular}




\begin{tabular}{lll}
\hline Log-likelihood & 277.62 & 42.40 \\
Akaike information criterion & -8.50 & -6.62 \\
Schwarz criterion & -8.02 & -6.40 \\
\hline
\end{tabular}

With respect to the table presented above, only third lag of FX returns is significantly explaining the present-day FX returns otherwise, all are found to be insignificant and this rendered only first model representing Sharif's regime is significant. In the case of statistical models, Sharif's regime is found to be robust on the basis of f-statistics, log-likelihood, AIC, R-squared, adjusted R-squared and SIC but the underlying reason for such behaviour could be that; Khan is currently ruling and the span he has served is smaller than what is served by Sharif. However, none of the regimes has rendered the relationship between stock returns and FX returns significant, therefore, the hypotheses pertaining to this cannot be accepted. Moreover, in Sharif's regime, the following impulse response has been generated:

Response to Cholesky One S.D. Innovations \pm 2 S.E.

Response of EXCHANGE_RATE to EXCHANGE_RATE

Response of EXCHANGE_RATE to STOCK_RETURNS
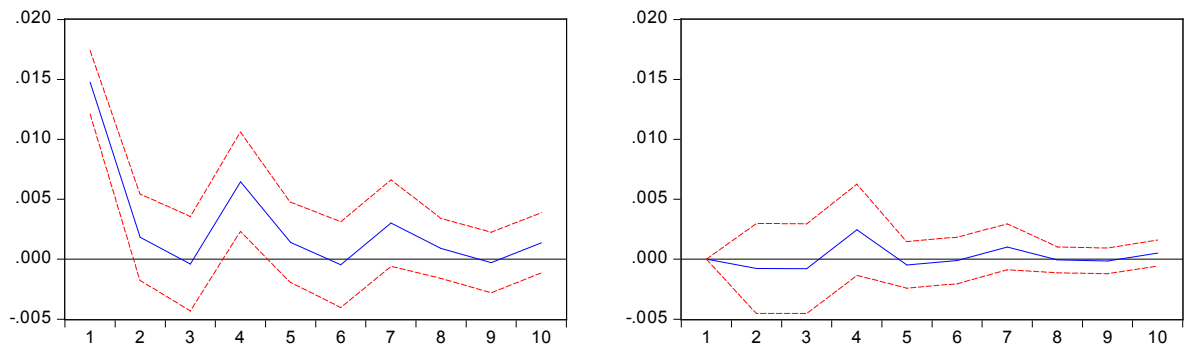

Response of STOCK_RETURNS to EXCHANGE_RATE

Response ofSTOCK_RETURNS to STOCK_RETURNS
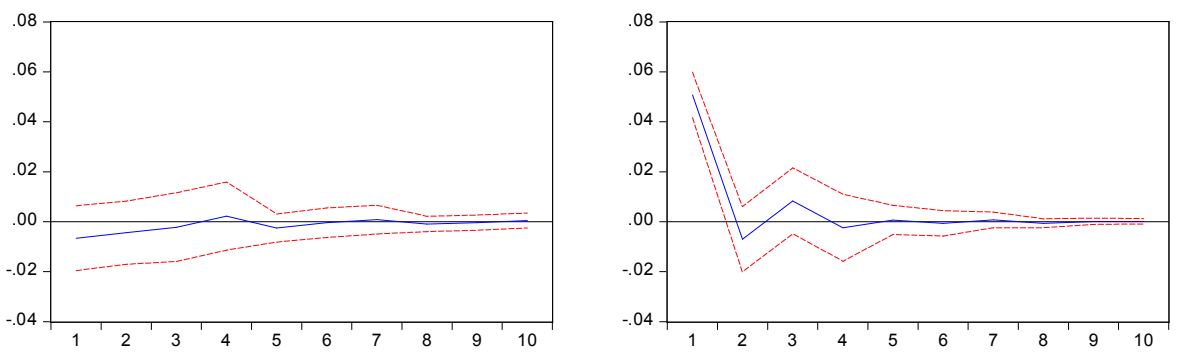

FIGURE 8

IMPULSE RESPONSE IN SHARIF'S REGIME

The impulse response of FX returns to the FX returns is significant at $1^{\text {st }}$, and $4^{\text {th }}$ periods whilst the impulse response of stock returns to stock returns is only significant at $1^{\text {st }}$ period. 

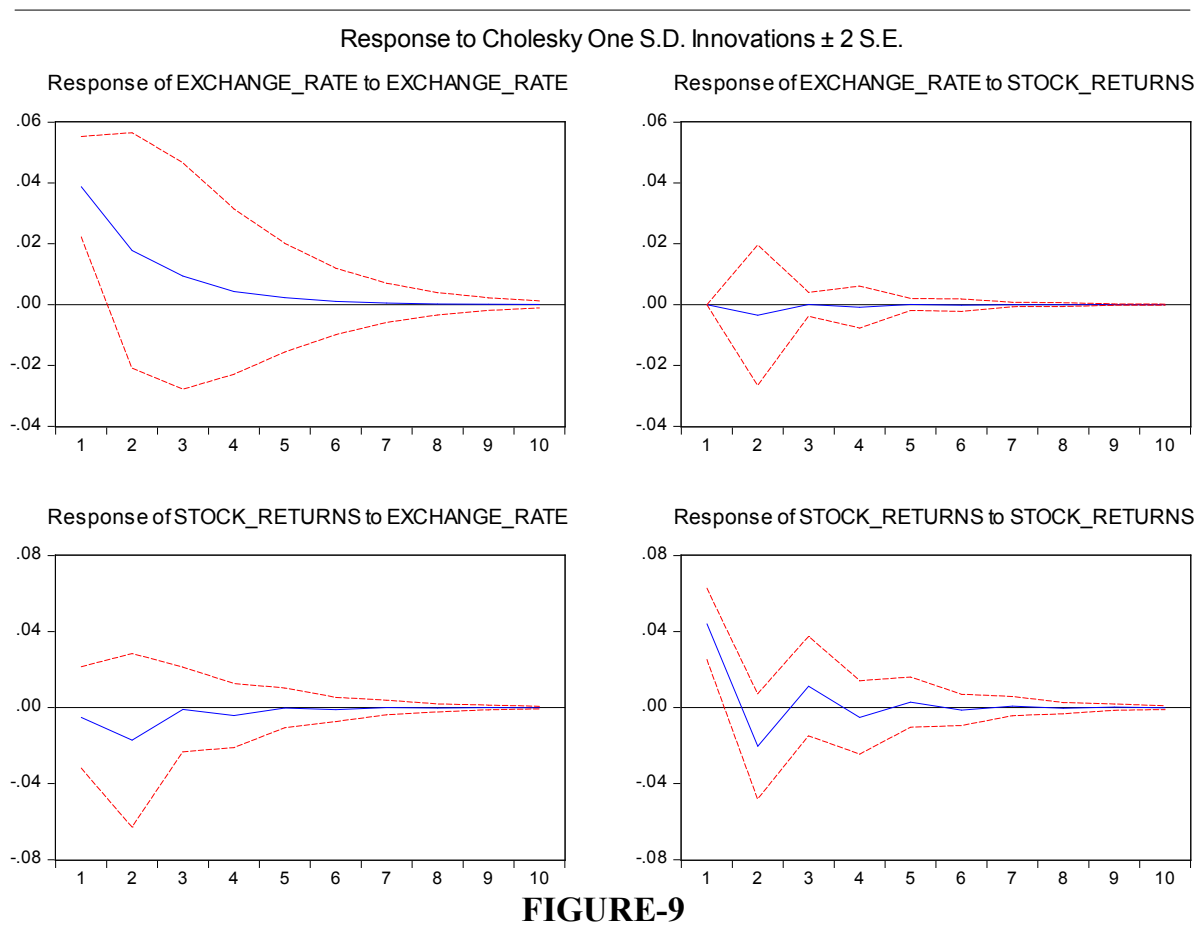

IMPULSE RESPONSE IN KHAN'S REGIME

Statistically, the impulse response in Khan's regime is different than that of Sharif. However, the impulse response of FX returns to itself is significant at the $1^{\text {st }}$ period and the impulse response of stock returns to itself is also significant during the $1^{\text {st }}$ period. All other responses can be seen as insignificant.

\section{DISCUSSION}

The research aimed to analyse the association of stock returns with the exchange rate (FX returns). The case of PSX (KSE-100 index) and USDPKR were considered specifically. In order to attain this aim, VAR and SVAR models were used. In addition, Khan's and Sharif's regimes were analysed separately as well. Overall, the relationship was found to be insignificant but a minor association of stock returns with FX returns' first lag is found to be significant (at 10\%). Therefore, it coincides with the findings of Suriani et.al., (2015) which was conducted on PSX earlier that the relationship was insignificant. However, in this research, a minor relationship is found asserting changes in the dynamics of Pakistan. On the other hand, in the case of a change in government and effect on the relationship between stock returns and FX returns, the findings are contradictory to the study of Caporale et.al., (2013) conducted on China. This implies that the dynamics of 
Pakistan are different from other developing countries. Cumulatively, it implies that minor association is found between stock returns and FX returns which is unidirectional. It further entails that worldwide, the association between the said variables is negated yet a unidirectional association is found in the case of Pakistan which can be regarded as a psychological influence on the investors. The plunges in the PKR following 2018 elections might have affected the investing behaviour in the stock market and as a result a minor is formed. Hence, it opens another dimension for further researchers where future researchers can analyse investors' behaviour or sentiment which has a potential of affecting the association between FX returns and stock returns.

\section{SUMMARY OF HYPOTHESES}

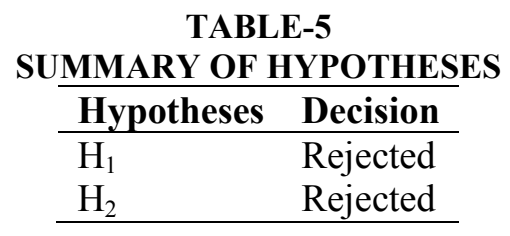

\section{CONCLUSION}

Conclusively, it has been explored that at 5\% level, the exchange rates of Pakistan (PKRUSD) is insignificantly associated with stock returns. Besides, it was also explored that the association of stock returns with the exchange rate is unidirectional at $10 \%$ significance level. Moreover, in the case of both Khan's and Sharif's regime, the association was found to be insignificant as well. However, the scope of this study was limited to a sample ranging from 2010 to 2019 which in future can be increased whilst frequency can be taken as daily to test whether the results are consistent or not. Henceforth, the cumulative findings of the study are found to be sustained by existing evidence and theories whereas, this research has opened another dimension to be explored which is investors' psychological behaviour.

\section{REFERENCES}

Abbas, Z. (2010). Dynamics of Exchange Rate and Stock Prices: A Study on Emerging Asian Economies (Doctoral dissertation, Mohammad Ali Jinnah University Islamabad).

Ali-Kemal, M., \& Haider, R.M. (2005). Exchange Rate Behaviour after Recent Float: The Experience of Pakistan, Paper Presented in $20^{\text {th }}$ Annual General Meeting and Conference of Pakistan Society for Development Economics.

Asad, H., Khan, A., \& Faiz, R. (2018). Behavioral Biases Across the Stock Market Investors: Evidence From Pakistan. Pakistan Economic and Social Review, 56(1), 185-209. 
Berg, K. E., \& Latin, R. W. (2008). Essentials of research methods in health, physical education, exercise science, and recreation. Lippincott Williams \& Wilkins.

Bhattacharya, B., \& Mukherjee, J. (2003). Causal Relationship between Stock Market and Exchange Rate, Foreign Exchange Reserves and Value of Trade Balance" Presented in $5^{\text {th }}$ Annual Conference on Money and Finance in India.

Camanho, N., Hau, H., \& Rey, H. (2018). Global Portfolio Rebalancing and Exchange Rates (No.w24320). National Bureau of Economic Research.

Caporale, G. M., Hunter, J., \& Menla Ali, F. (2013). On the linkages between stock prices and exchange rates: evidence from the banking crisis of 20072010.

Chatterjee, S., \& Mursagulov, A. (2016). Fiscal policy and the real exchange rate. Macroeconomic Dynamics, 20(7), 1742-1770.

Clerc, L., Drumetz, F., \& Haas, F. (2002). The influence of structural changes on market functioning and its implications for monetary policy: a focus on the euro area. BIS Papers, (12), 43-64.

Creswell, J. W., \& Creswell, J. D. (2017). Research design: Qualitative, quantitative, and mixed methods approaches. Sage publications.

Davidson, J., Thornton, M. \& Hashimzade, N., (2013). Cointegration and error correction. Handbook of Research Methods and Applications on Empirical Macroeconomics, 165-188.

Diamandis, P.F., \& Drakos, A.A. (2011). Financial liberalization, exchange rates and stock prices: Exogenous shocks in four Latin American countries. Journal of Policy Modelling, 33, 381-394.

Evans, G. R., \& Edition July, F. (2014). Exchange Rates. March, 14.

Gay, R. D. (2016). Effect of macroeconomic variables on stock market returns for four emerging economies: Brazil, Russia, India, and China. International Business \& Economics Research Journal (IBER), 15(3), 119-126.

Glaser, K. (2014). Inductive or deductive?: The impact of method of instruction on the acquisition of pragmatic competence in EFL. Cambridge Scholars Publishing.

Haughton, A. Y., \& Iglesias, E. M. (2017). Exchange rate movements, stock prices and volatility in the Caribbean and Latin America. International Journal of Economics and Financial Issues, 7(2), 437-447.

Huang, X. (2017). Exchange rate movements and export market dynamics: evidence from China. Economics: The Open-Access, Open-Assessment EJournal, 11(2017-23), 1-27.

Hussain, N., \& Khan, A. Q. (2014). An Analysis of the Stock Return and Exchange Rate Variation on Market Return of Pharmaceutical Industry in Pakistan. World Applied Sciences Journal, 31(6), 1180-1187.

Khatri, S. N., Kashif, M., \& Shaikh, A. S. (2017). The Exchange Rate as Significant Predictor of Movement in Stock Market Indices in South Asian 


Countries: An Econometric Analysis. Journal of Business
Strategies, 11(2), 107-123.

Kilian, L., \& Lütkepohl, H. (2017). Structural vector autoregressive analysis. Cambridge University Press.

Montgomery, D. C., Jennings, C. L., \& Kulahci, M. (2015). Introduction to time series analysis and forecasting. John Wiley \& Sons.

Sharma, N. (2016). Causal relation between stock return and exchange rate: Evidence from India. Global Journal of Management and Business Research.

Sichoongwe, K. (2016). Effects of exchange rate volatility on the stock market: The Zambian experience. Journal of Economics and Sustainable Development, 7(4).

Suriani, S., Kumar, M. D., Jamil, F., \& Muneer, S. (2015). Impact of exchange rate on stock market. International Journal of Economics and Financial Issues, 5(1S), 385-388.

Tripathi, V., \& Kumar, A. (2014). Relationship between Inflation and stock returns-evidence from BRICS markets using Panel Co integration Test. International Journal of Accounting and financial reporting, 4(2), 647-658.

Wang, Y.C., Tsai, J.J. \& Li, Q., (2017). Policy impact on the Chinese stock market: From the 1994 bailout policies to the 2015 Shanghai-Hong Kong stock connect. International Journal of Financial Studies, 5(1), 4.

Zaidi, E. (2019). Dollar hits record high, stocks plunge. [Online] Available at: https://www.thenews.com.pk/print/472225-dollar-hits-record-highstocks-plunge [Accessed 30 Aug. 2019].

Zhao, H. (2010). Dynamic relationship between exchange rate and stock price: Evidence from China. Research in International Business and Finance, 24(2), 103-112.

Zubairi, D. (2019). Dollar hits historical high at Rs148 intraday in interbank market. [Online] DAWN.COM. Available at: https://www.dawn.com Lnews/1482642 [Accessed 19 Jul. 2019]. 